\title{
Active monitoring at an active volcano: amplitude-distance dependence of ACROSS at Sakurajima Volcano, Japan
}

\author{
Koshun Yamaoka ${ }^{1 *}$, Hiroki Miyamachi², Toshiki Watanabe ${ }^{1,5}$, Takahiro Kunitomo ${ }^{1}$, Tsuyoshi Michishita ${ }^{1,6}$, \\ Ryoya Ikuta ${ }^{3}$ and Masato Iguchi ${ }^{4}$
}

\begin{abstract}
First testing of volcanic activity monitoring with a system of continuously operatable seismic sources, named ACROSS, was started at Sakurajima Volcano, Japan. Two vibrators were deployed on the northwestern flank of the volcano, with a distance of $3.6 \mathrm{~km}$ from the main crater. We successfully completed the testing of continuous operation from 12 June to 18 September 2012, with a single frequency at $10.01 \mathrm{~Hz}$ and frequency modulation from 10 to $15 \mathrm{~Hz}$. The signal was detected even at a station that is $28 \mathrm{~km}$ from the source, establishing the amplitude decay relation as a function of distance in the region in and around Sakurajima Volcano. We compare the observed amplitude decay with the prediction that was made before the deployment as a feasible study. In the prediction, we used the existing datasets by an explosion experiment in Sakurajima and the distance-dependent amplitude decay model that was established for the ACROSS source in the Tokai region. The predicted amplitude in Sakurajima is systematically smaller than that actually observed, but the dependence on distance is consistent with the observation. On the basis of the comparison of the noise level in Sakurajima Volcano, only 1-day stacking of data is necessary to reduce the noise to the level that is comparable to the signal level at the stations in the island.
\end{abstract}

Keywords: Artificial source; Seismic velocity; Distance-dependent attenuation

\section{Background}

Many observation methods are used in monitoring volcanic activity to estimate the migration of magma associated with volcanic eruptions. Crustal deformation is widely used in volcano monitoring to obtain information on the pressure source beneath volcanoes. Leveling surveys in and around volcanoes have long been used to detect the location and the pressure change of magma chambers since the pioneering work of Omori (1916) and a model calculation by Mogi (1957). Data of leveling surveys are also used for detecting the intrusion of dykes (e.g., Hashimoto and Tada 1990). Quantitative modeling of dykes has been widely used using the comprehensive formulation by Okada (1985). Since the innovative success of Global Positioning System (GPS), geodetic networks

\footnotetext{
* Correspondence: kyamaoka@seis.nagoya-u.ac.jp

'Earthquake and Volcano Research Center, Graduate School of Environmental Studies, Nagoya University, Furo-cho, Chikusa-ku, Nagoya 464-8601, Japan

Full list of author information is available at the end of the article
}

have been established in many volcanoes, and their crustal deformations are monitored in near-real time. The crustal deformations are usually interpreted as inflation or deflation of magma reservoirs or dyke intrusions.

Seismic activities have also long been used to monitor volcanic activities. Activation or deactivation of earthquakes, changes in hypocenter distribution, and types of earthquakes are widely used as empirical tools to warn volcanic eruptions. McNutt (1996) proposed a generic swarm model of volcanic earthquakes to evaluate the temporal sequence of volcanic activity. Intrusions of dykes are usually inferred from hypocenter migrations (e.g., Sakai et al. 2001 for the Miyakejima Volcano). Longperiod (LP) events or volcanic tremors are used to infer magma or hydrothermal activity in volcanoes. Very long period (VLP) events, especially, are used to model the vibration of magma plumbing systems (e.g., Kumagai 2006).

Electromagnetic observations are generally used for monitoring thermal activity of volcanoes. Heating or cooling of rocks in volcanoes can be detected with the

\section{实}


increase or decrease of magnetic fields near volcanoes. Emplacement of magma or changes in hydrothermal activity affect the resistivity structure beneath volcanoes, which can be monitored by electromagnetic surveys. For example, pre-eruptive activity of the caldera formation at Miyakejima Volcano in 2000 was monitored with magnetic and electric field variations (Sasai et al. 2002).

Temporal changes in the propagation properties of seismic wave are a relatively new tool for monitoring volcanic activities. $S$-wave splitting has been regarded as a stress measure (Crampin 1994) and used for monitoring volcanic activity (e.g., Gerst and Savage 2004). Seismic interferometry using passive sources, such as ambient noise, has recently been applied to detect the temporal variation of seismic propagation in volcanic regions to monitor their activity. Grêt and Roel (2005) monitored temporal changes of the seismic structure in Mt. Erebus with coda wave interferometry from December 1999 to February 2000, suggesting that the change of cross correlation between two different seismic events might indicate changes in the uppermost lava lake. Seismic interferometry has been applied to other volcanoes, such as Merapi (SensSchoenfelder and Wegler 2006) and Reunion Volcanoes (Brenguier et al. 2008), to monitor the temporal changes in volcanic activity.

Active sources are also used to detect temporal variations of seismic propagation properties in volcanoes, though few trials have been made. Active sources have an advantage over natural sources in that source parameters such as time and location are well constrained. Nishimura et al. (2005) examined a temporal change in seismic velocity by repeating six explosion sources in a 6-year period near Iwate Volcano throughout its active period. Tsutsui et al. (2011) conducted repeating reflection seismic surveys in Sakurajima Volcano to investigate the temporal changes in reflection image.

Traditional artificial sources were used for monitoring seismic propagation properties using repeating operations with regular time intervals. Explosive or impact sources, which have been frequently used, can destroy the ambient rocks and could change the propagation property around the source. To overcome such shortcomings, a controlled source for long-term continuous monitoring, named ACROSS, which stands for Accurately Controlled Routinely Operated Signal System, was developed (Kumazawa and Takei 1994). In the ACROSS, the seismic signal is generated by the centrifugal force of a rotating eccentric mass. The rotation is highly stabilized to maximize the stacking performance in order to increase the signal-tonoise ratio. The transfer functions between the source and receivers are calculated with a convolution of received signals with the source signal.

ACROSS was first deployed in 1996 at two test sites, Awaji Island and Tono region in Japan, to evaluate its performance. The rotation is accurately controlled by an AC servo motor with a feedback inverter, and the rotational angle is synchronized to the pulse sequences given by a GPS clock. As most of the seismic stations are operated with reference to a GPS clock, we can establish a remote synchronization between the ACROSS source and seismic stations (Yamaoka et al. 2001). Fifteen months of monitoring at Awaji site started in January 2000, and it succeeded in detecting a temporal change associated with strong ground motion by nearby earthquakes (Ikuta and Yamaoka 2004), which shows a sudden delay and gradual recovery of seismic velocity, presumably due to ground water movement.

\section{Methods}

\section{Deployment of ACROSS in Sakurajima Sakurajima Volcano}

Sakurajima Volcano, Japan, is one of the most active volcanoes in the world and is located in the southern part of Kyushu Island, Japan. Sakurajima Volcano is a small island and is located at the rim of the Aira Caldera that produced a gigantic silicic eruption about 25,000 years ago (Aramaki 1969). Sakurajima Volcano experienced flank and summit eruptions in historic times (Kobayashi and Tameike 2002). Violent eruptions with effusion of andesitic lava took place in $1476,1779,1914$, and 1946 . The volume of lava in the 1914 eruption was about $1.5 \mathrm{~km}^{3}$ (Ishihara et al. 1981), and the flow covered the channel between the Sakurajima and Kyushu Islands. The results of instrumental observations for recent eruptive activities are summarized by the Japan Meteorological Agency (2013). The current eruptive activity started in 1955 and remained at a high level from 1974 to 1992 . After this period, Sakurajima was less active until 2006. The eruption activity started anew in June 2006 from the Showa Crater located about 500 m east of the Minamidake Crater, which has been active and exploded tens of thousands of times since 1974. The number of explosions at the Showa Crater amounts to more than a thousand in 2010. Studies on crustal movement revealed two main magma sources in and around Sakurajima Volcano (Ishihara 1990), showing a large magma source beneath the Aira Caldera located at a depth of about $10 \mathrm{~km}$ below sea level, and a small magma source located about $4 \mathrm{~km}$ beneath the summit of Sakurajima Volcano. Hidayati et al. (2007) estimated the location of magma sources by analyzing volcano tectonic earthquakes. They showed that a magma source exists at a depth of $5 \mathrm{~km}$ and small magma pockets are distributed vertically from the depths of 2 to $4 \mathrm{~km}$ below the summit.

\section{Deployment of ACROSS}

We deployed the ACROSS source at the northwestern flank of Sakurajima Volcano in March of 2012. We selected the grounds of a garbage incineration facility, 
which is no longer used, for the source site of ACROSS. We deployed sources, lubricant circulators, a power control gear, and a PC-based controller in a garage as shown in Figure 1. We used two vibrators with the same specifications to cover a wider frequency range and stronger force than with a single vibrator. The vibrators we used produce a sinusoidal force by rotation of an eccentric mass around a vertical axis. The force is proportional to the square of the rotational frequency and is $1.0 \times 10^{5} \mathrm{~N}$ at $25 \mathrm{~Hz}$. The vibrators are firmly fixed to a foundation that is made of steel-reinforced concrete, with a steelbeamed frame within it. The foundation is made in a rectangular pit, which is excavated in a pyroclastic deposit, with a dimension of $2 \mathrm{~m}$ in depth and $3.8 \mathrm{~m} \times$ $4.3 \mathrm{~m}$ in length and width. The three-component accelerometer is attached to the foundation to record its movement, which is used to correct the temporal changes in the vibration of the source.

A PC-based controller that can make precise operations on the motor is the essential part of ACROSS (Kunitomo and Kumazawa 2004). It consists of a GPS clock (XL-DC, TrueTime Inc., Santa Rosa, CA, USA), pulse generators (ACROSS-SG2, Digital Signal Technology Inc., Asaka, Japan), and control software (ROSETTA2012) on a Windows PC. The pulse generator provides a series of pulses to the power control gear, which drives the AC servo motor so that the rotation angle is proportional to the number of pulses given to it. The timing of pulses produced by the pulse generator is precisely synchronized to the GPS clock. Therefore, this pulse generator can drive the vibrator so that it produces a sinusoidal force with frequency modulation (FM) by expanding and shrinking the intervals of pulses. In ACROSS, the FM operation is a fundamental technique

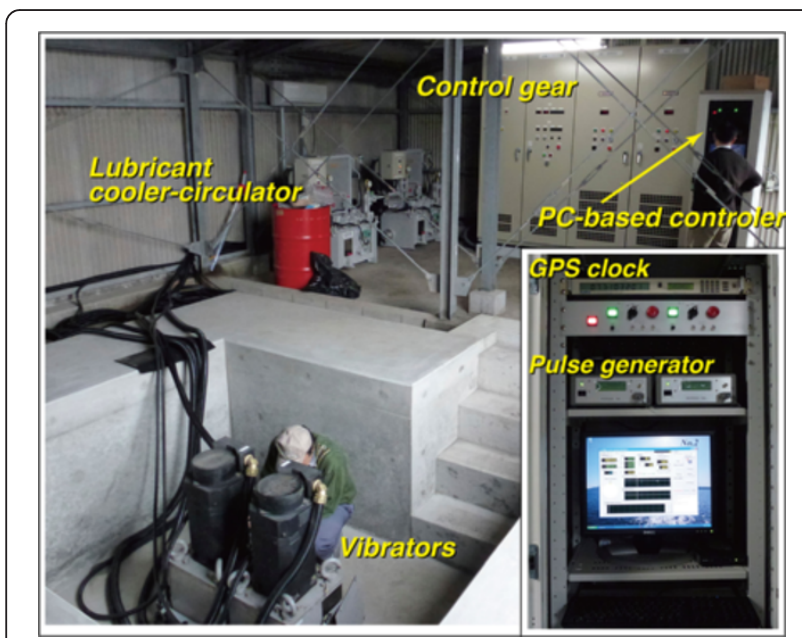

Figure 1 ACROSS that is deployed in Sakurajima Volcano. Two vibrators are fixed to the foundation made of reinforced concrete. The photograph in the inset shows the PC-based control system. to produce plural sinusoids simultaneously with one vibrator.

The control software has multiple functions. It monitors the states of the mass rotation, such as the rotational velocity, mass position, and motor torque. The notable function of the software is to switch the rotation direction automatically at regular time intervals. The switching interval is usually chosen to be either 1 or $2 \mathrm{~h}$. We can synthesize a linear vibration in any direction with a combination of clockwise and anticlockwise rotations. This means that we can monitor the temporal variation of seismic propagation properties for multiple excitation directions. As the vibrator rotates around the vertical axis, radial and transverse vibrations with reference to the station direction are synthesized to obtain the transfer function related to $P$ and $S$ waves, respectively, which is a great advantage of the system.

The source site has Internet connection for remote monitoring and remote control of ACROSS. This dramatically reduces the frequency of maintenance visits. In the summer time, electric power outages and vibrator stoppages occur frequently due to unstable weather conditions, including heavy rain and typhoons with lightning. The vibrators can be restarted via the Internet connection using a VNC protocol, which enables us to stop or restart the vibrator remotely, without visiting the site. The rotation frequency and phase, the motor torque, and oil temperature are monitored and recorded by the PC to infer the cause of any troubles, shortening the time before repairs. A web camera with a microphone is also deployed at the vibrators' location so that the lubricant circulators, the control gear, and $\mathrm{PC}$-based controllers are visible, making it easy to perform a visual inspection of the system.

\section{Results}

\section{First signal test}

The first test operation began on 12 June 2012 and continued until 17 September 2012, for 97 days. During this test period, one vibrator was operated with a single frequency at $10.01 \mathrm{~Hz}$, and the other was operated with FM from 10 to $15 \mathrm{~Hz}$ and a modulation period of $50 \mathrm{~s}$. We chose $10.01 \mathrm{~Hz}$ for the single frequency so as not to overlap with the frequency components produced by the other vibrator in FM operation. The FM operation produces a series of sinusoids from 10.00 to $15.00 \mathrm{~Hz}$ with a $0.02-\mathrm{Hz}$ interval. The rotation direction was switched every $2 \mathrm{~h}$ to synthesize two independent linear excitation forces. The received signals of two sequential operations, one of which is clockwise and the other is anticlockwise rotation of the source, are linearly combined with an appropriate phase shift. This operation synthesizes the signals at the seismic stations by radial and transverse linear excitations. The rate of operation in the first test period was $88 \%$. The main cause of the suspension was 
power instability or failure due to lightning or storm around the site. In most cases, the system was restarted remotely.

The signal from the ACROSS sources is recorded by seismic stations that are routinely operated for monitoring seismic and volcanic activity. Figure 2 shows the location of seismic stations that are used for receiving the signal from the ACROSS source. We used nine stations in Sakurajima Island and six stations in the surrounding region, which are operated by the Disaster Prevention Research Institute (DPRI) of Kyoto University, Faculty of Science of Kagoshima University and National Research Institute of Earth Science and Disaster Prevention (NIED). The data of all stations are synchronized to a GPS clock, which guarantees remote synchronization to the source signal of ACROSS.

Figure 3 shows the spectra for the representative three observation stations with 2.5 months' stacking from 13 June 2012. Station KORH (Hi-net Koriyama station) is located off Sakurajima Island, KURN (Kurokami station) is located on the other side of the summit on the island, and HAR (Harutayama station) is located in a deep borehole close to the source site. For each station, the spectra of three directional components of the seismometer are shown for both radial and transverse linear sources that are synthesized by combinations of clockwise and anticlockwise rotations. The notations attached after the station code indicate the combinations of the components at the sources and the receivers. The first letters, which are in capitals, indicate the component at the receiver. $\mathrm{U}, \mathrm{R}$, and $\mathrm{T}$ indicate the vertical, radial, and transverse components, respectively. The second letters, which are in lower case, indicate the component at the source, where $\mathrm{r}$ and $\mathrm{t}$ indicate the radial and transverse components, respectively. Hereafter, we shall use this convention in this paper.

The unit of spectral amplitude is adjusted to meters per second $(\mathrm{m} / \mathrm{s})$, which represents the amplitude of a single sinusoidal wave. Note that the amplitude unit in this spectrum plot is not $(\mathrm{m} / \mathrm{s}) / \mathrm{Hz}^{1 / 2}$ which is generally used in conventional spectrum plots. We adopt the unit $\mathrm{m} / \mathrm{s}$, because the signal emitted from ACROSS is composed of a finite number of sinusoids with constant amplitudes. In this unit, the amplitude of ACROSS signals in the frequency domain stays constant, independent of the stacking length. If we adopt $(\mathrm{m} / \mathrm{s}) / \mathrm{Hz}^{1 / 2}$, the spectral peaks of the ACROSS signal increase with the length of the stacking period, while the noise level stays constant. We prefer $\mathrm{m} / \mathrm{s}$ for the amplitude unit to make the ACROSS signal invariable while noise levels decrease proportionally to the square root of the stacking time period.

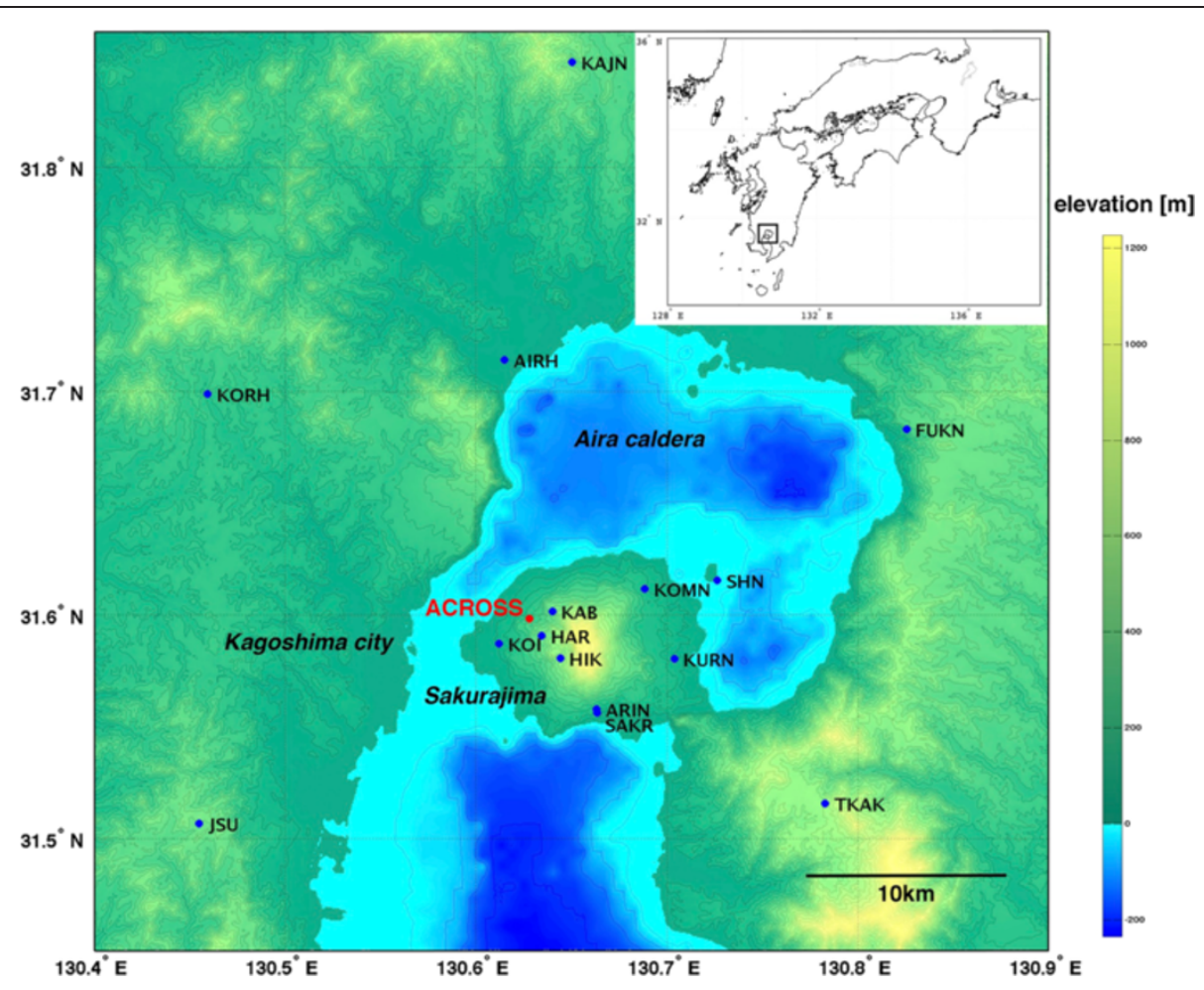

Figure 2 Location of the ACROSS source and seismic stations on and off Sakurajima Volcano, Japan. Red circle shows the location of the ACROSS source. Blue circles labeled with codes are the seismic stations we used. The elevation is shown by color scale, where land area is colored by green to yellow and sea area is colored by cyan to blue. 
(a)
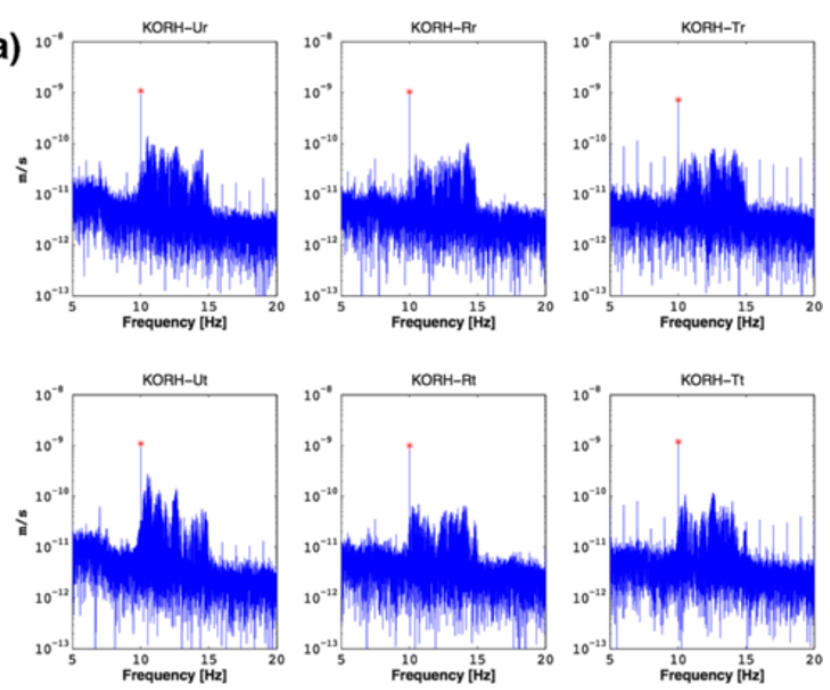

(b)
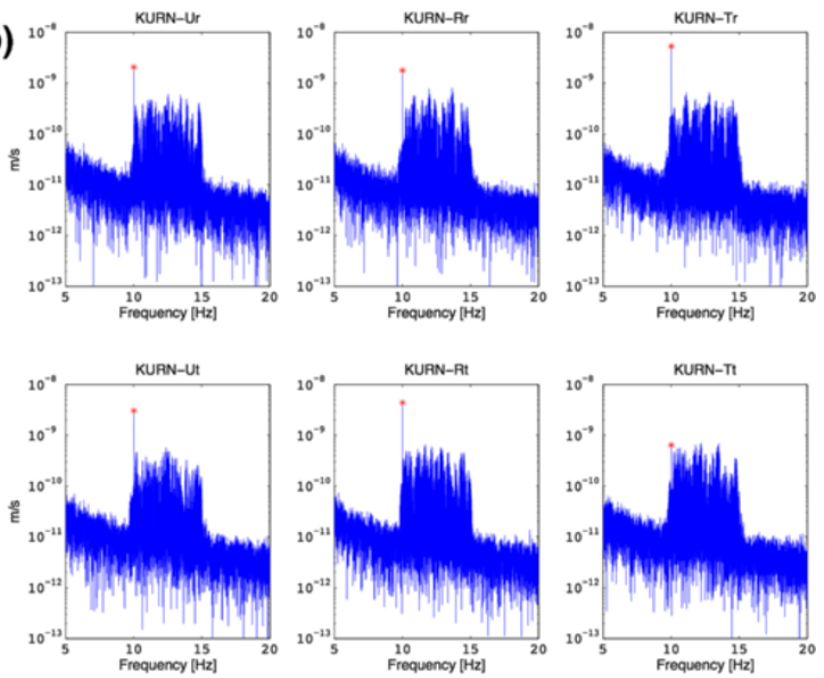

(c)
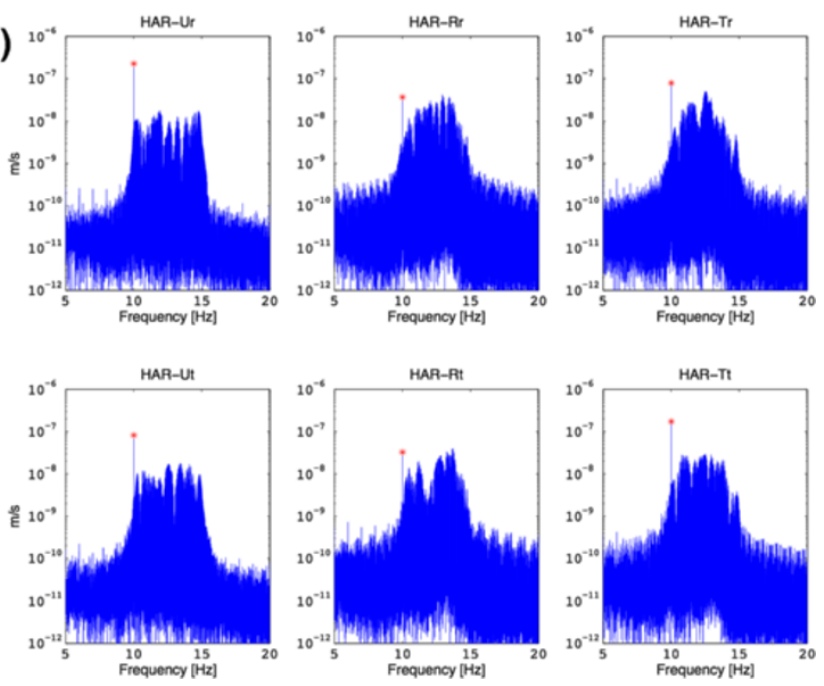

Figure $\mathbf{3}$ (See legend on next page.) 
(See figure on previous page.)

Figure 3 Amplitude spectrum at seismic stations after stacking. The spectra are calculated with a Fourier transform over $400 \mathrm{~s}$ long with 100- $\mathrm{Hz}$ sampled data, which are obtained by stacking the entire observation period from 13 June to 17 September 2012. Components are indicated by the combinations of $U, R, T$ and $r$, t. The labels $U, R$, and $T$ indicate the vertical, radial, and transverse components at the seismic station, respectively. The labels $r$ and $t$ indicate linear force in the radial and transverse directions at the source, respectively. The spectra for linear forces are synthesized with the combination of clockwise and anticlockwise rotation of the source. In each figure, the peak marked with a star indicates the signal at $10.01 \mathrm{~Hz}$. The groups of spectral peaks between 10 and $15 \mathrm{~Hz}$ are the signals of FM operation of the ACROSS source. (a) Signal spectrum at KORH. (b) Signal spectrum at KURN. (c) Signal spectrum at HAR. See their locations in Figure 2.

The signal from the source that is operated in a single frequency $(10.01 \mathrm{~Hz})$ is clearly seen even at the stations off Sakurajima Island. The station KORH (Figure 3a), which is located $19.5 \mathrm{~km}$ from the source site, shows a clear spectral peak at $10.01 \mathrm{~Hz}$, with a signal-to-noise ratio (SNR) of about 100 in all the components, with a stacking length of 88 days. The signal of the source in FM operation is also seen in the spectrum from 10 to $15 \mathrm{~Hz}$. The station KURN (Figure 3b), which is located $7.5 \mathrm{~km}$ from the source site on the other side of the summit, shows clear spectral peaks. The SNRs are larger than those at KORH, even though the stacking period is 71 days. The signal at HAR (Figure 3c), which is located $1.1 \mathrm{~km}$ from the source site, has a very good SNR not only because of the distance, but also because of the low-noise environment in the deep borehole. The SNR for a single sinusoid at $10.01 \mathrm{~Hz}$ is about 1,000 for most of the components, and the SNR for the FM signal is about 100 . Other spectral peaks, which are typically seen at $\mathrm{KORH}$, are caused by the data telemetry system at the station. Small noise that is synchronized to the GPS clock is generated in the data telemetry system, resulting in spectral peaks with multiples of exactly $1.0 \mathrm{~Hz}$.

Based on the spectral data for all the stations in Figure 3, we plot the amplitudes of the ACROSS signal to show the amplitude decay as a function of the distance from the source in and around Sakurajima Island (Figure 4). We plot the amplitude of the signals for the vibrations with both the single frequency operation at $10.01 \mathrm{~Hz}$ and the FM operation from 10 to $15 \mathrm{~Hz}$. Amplitudes are also plotted for the radial and transverse linear vibrations to show the difference between the two vibration directions. The

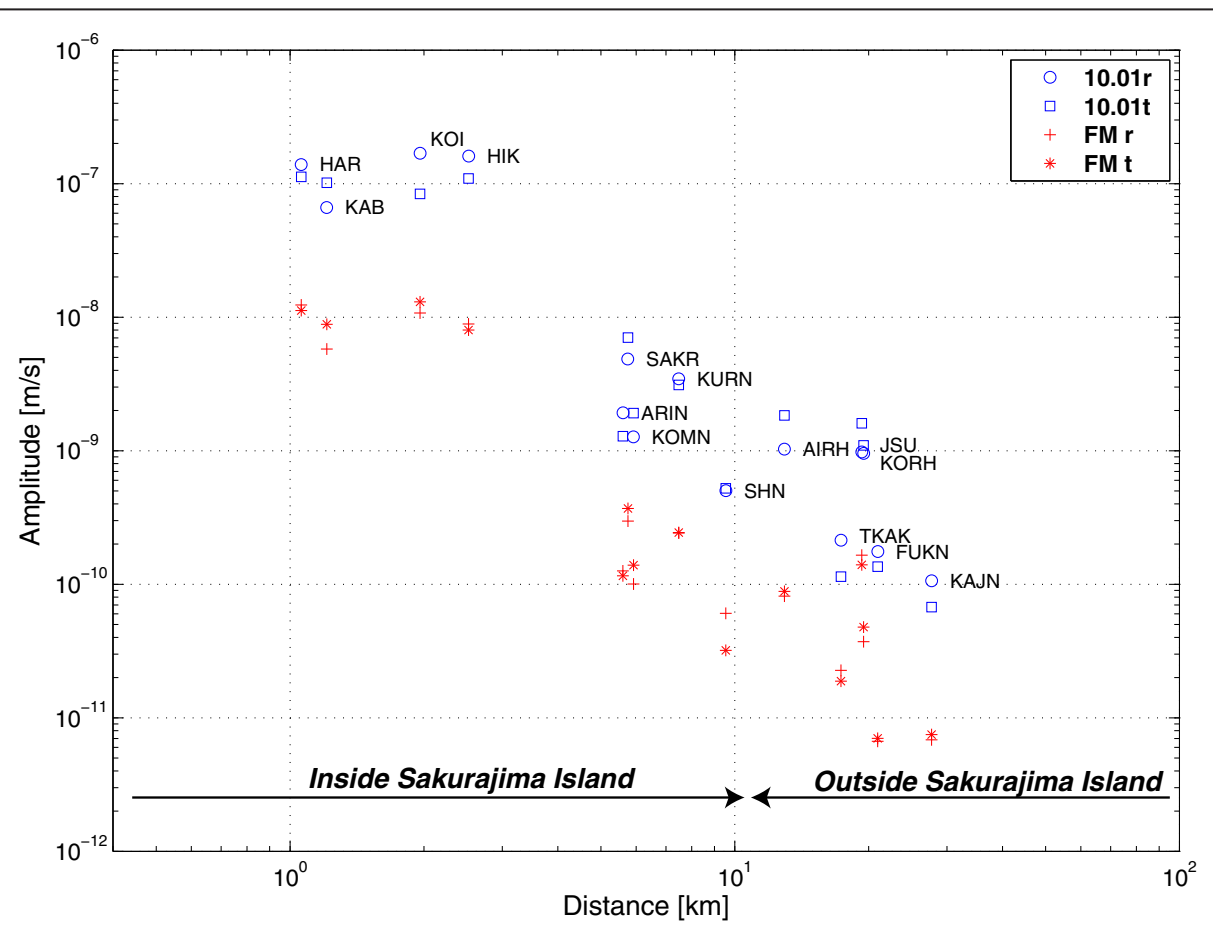

Figure 4 Amplitude of ACROSS source observed at the stations on and around Sakurajima Island. Open circles and squares show the root mean square (RMS) amplitudes of three components by a single sinusoidal source at $10.01 \mathrm{~Hz}$, corresponding to the source in radial and transverse linear vibration, respectively. Pluses and stars show RMS amplitudes for signals with FM operation in radial and transverse vibrations, respectively. 10.01r and $10.01 \mathrm{t}$ indicate the radial and transverse vibrations, respectively, for single sinusoidal source at the 10.01- $\mathrm{Hz}$ operation. FM r and FM t indicate the radial and transverse vibrations, respectively, for FM operation. The RMS amplitudes for the FM signal are calculated for the spectral peaks between 10.0 and $15.0 \mathrm{~Hz}$. Station codes are labeled with the markers of $10.01 \mathrm{r}$. 
amplitude of FM operation at each station is calculated using the root mean square (RMS) of spectral peaks between 10.0 and $15.0 \mathrm{~Hz}$, in which 251 peaks are included at $0.02-\mathrm{Hz}$ intervals. The amplitude decays are roughly inversely proportional to the square of the distance from the source for both single frequency and FM signals. The mean amplitude of the FM signal is an order of magnitude smaller than that of the single frequency signal for most of the stations. This ratio is reasonable considering that the generated force of ACROSS is proportional to the square of the rotational frequency, and the seismic energy of the single sinusoid is distributed among 250 sinusoids in FM operation.

As one of the ACROSS sources is operated with a frequency modulation, we can convert the signal into a transfer function in the time domain. In this process, the signal at each station is deconvoluted with the source signal in the frequency domain. Figure 5 shows the transfer functions for the seismic station we used, which are aligned as a function of distance. The two representative components of transfer functions are plotted. The top panel shows the Ur component in which $P$ waves are emphasized, whereas the bottom panel shows the Tt component in which $S$ waves are emphasized. In both panels, the signal is more scattered into later parts for the distant stations than for nearby stations. There seems to be no predominant later phases in the signals, probably because of the complex structure in the volcano region. The onsets of $P$ and $S$, as well as the detail of the later phases, are not clear because of narrow bandwidth between 10 and $15 \mathrm{~Hz}$.
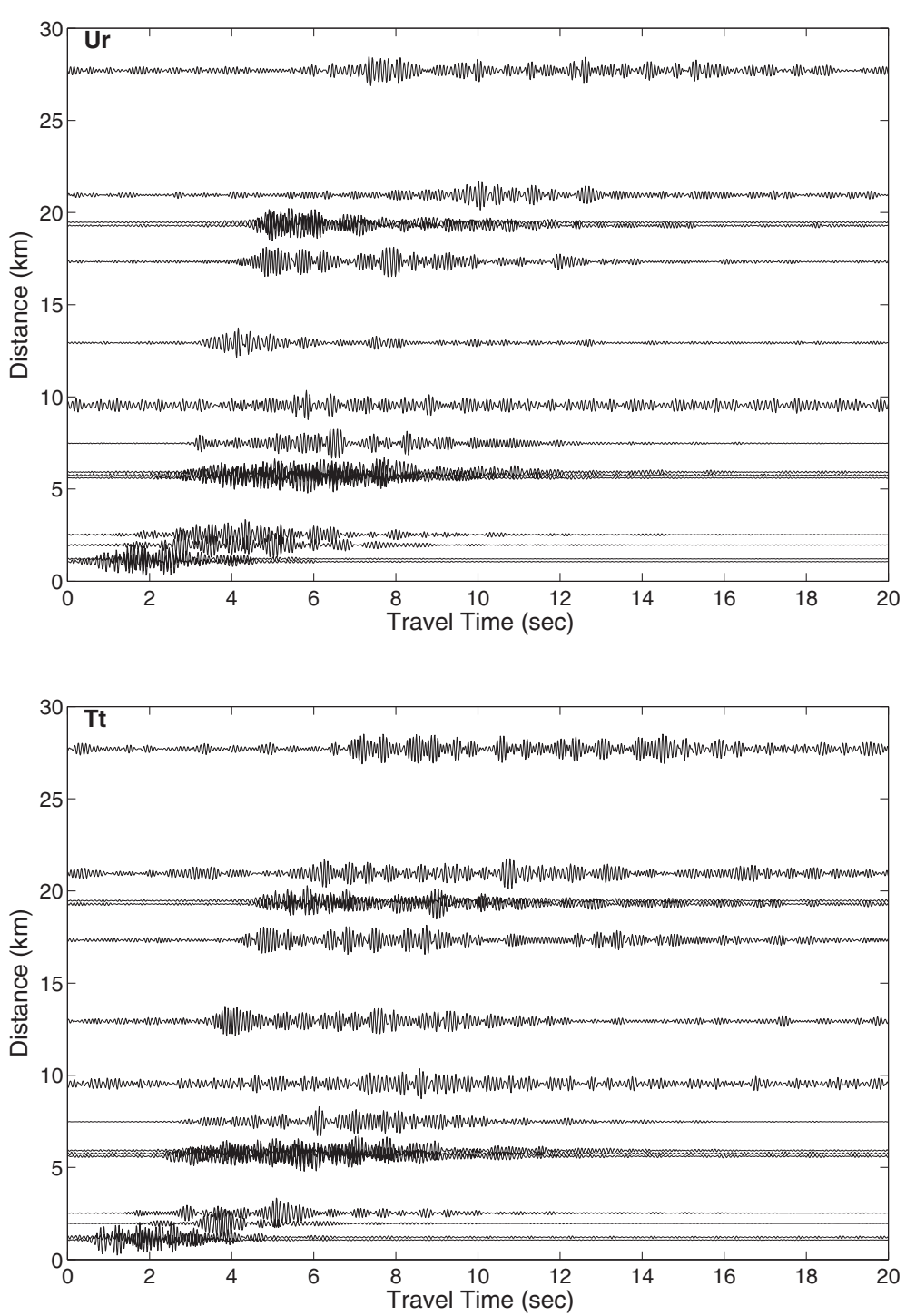

Figure 5 Transfer functions in time domain for the ACROSS source in Sakurajima. Ur (vertical component of the receivers by radial source excitation) and Tt (transverse component of the receivers by transverse source excitation) components are shown. 
We will use a wider frequency range and make more detailed discussions, such as temporal changes of the travel time, in future experiments.

\section{Comparison to Toyohashi site}

The same models of ACROSS vibrators were already in operation at the Toyohashi site in the Tokai region, Japan, when ACROSS was deployed in Sakurajima. We have been operating the ACROSS at Toyohashi site to monitor the temporal change of seismic propagation property associated with the subduction process of the Philippine Sea plate. In addition, we deployed an ACROSS at Sakurajima Volcano for monitoring its activities. Before the deployment, we investigated the detectability of signal from the ACROSS source that was to be deployed in Sakurajima using the observation data in the Tokai region with ACROSS at Toyohashi. In this section, we show the results of the investigation comparing them with the actual observational result. To assess the feasibility of signal detection at Sakurajima, we used the amplitude decay relation as a function of distance obtained in the monitoring experiment of ACROSS in the Tokai region and an explosion experiment in Sakurajima. The process shown here is useful to assess the feasibility of using ACROSS at any other locations.

\section{Explosion experiment at Sakurajima}

An explosion experiment for which we analyzed the amplitude decay as a function of distance was carried out in 2008 in and around Sakurajima Island (Iguchi et al. 2009). We compared the amplitude decays between the explosion source and the ACROSS source in the Tokai region.

We first estimated amplitude decay as a function of the source distance in and around Sakurajima. We used waveform data obtained in the seismic exploration experiment with densely deployed seismometers that was conducted in and around Sakurajima Volcano in November 2008. In the experiment, 15 dynamite sources (hereafter referred to as shot sources), 426 temporary-deployed one-component seismic stations on land, and 32 oceanbottom seismometers were used. Velocity type sensors with the natural period of $2.2 \mathrm{~Hz}$ were used on land, and $4.5 \mathrm{~Hz}$ on the ocean bottom. These seismometers were deployed with 200-m intervals on Sakurajima Island and at 400- to 500-m intervals around the island. Each station recorded seismic waves from every shot for $60 \mathrm{~s}$ with a $250-\mathrm{Hz}$ sampling frequency. The purpose of this experiment was to delineate seismic structure over an area of Aira Caldera (Miyamachi et al. 2013). In this study, we used the data from seismic stations on land that are shown in Figure 6.

From the experiment dataset, we used the record of shot 2 (S02 in Figure 6) for the estimation of amplitude decay with distance. Shot 2 was located close to the ACROSS source site and is suitable for comparison. Although there were several other shots that were closer to the ACROSS site than shot 2, we do not use them because their dynamite weight was only $20 \mathrm{~kg}$, while the dynamite for shot 2 weighed as much as $200 \mathrm{~kg}$.

Figure 7 shows the signal traces of shot 2 . The traces are aligned according to the distance from the shot point. The first $10 \mathrm{~s}$ of the data after the first arrival is used and indicated in bright red color. The first arrivals are identified using a variance ratio between 1-s sections before and after a point. We look for the point that has the largest variance ratio in a trace, which is regarded as the first arrival. The first arrivals are satisfactorily identified to select the 10-s-long data to evaluate the amplitude. The traces for the stations on Sakurajima Island, which are indicated by blue lines before first arrivals, have no marked later phases. Some of the traces for the stations with source distances between 16 and $19 \mathrm{~km}$, which are located off Sakurajima Island, have clear later phases. The stations are located on the plain to the north of Sakurajima Island; therefore, the waves are regarded as having traveled through sediments. The waveforms of the stations that are close to the shot point are clipped. We do not use the clipped or noisy data, which are indicated by gray lines in the figure.

The waveforms are converted into the frequency domain by a Fourier transform. Mean values of the power spectrum are calculated in the two frequency bands, between 5 and $15 \mathrm{~Hz}$ and 10 and $20 \mathrm{~Hz}$. The two frequency bands ( 5 to $15 \mathrm{~Hz}, 10$ to $20 \mathrm{~Hz}$ ) correspond to those of the two sources at Toyohashi. We plot the root mean square of the amplitude at the seismic stations against the source distance and fit the plot with the following equations:

$$
\begin{aligned}
& A=a \frac{\exp (-b x)}{x} \\
& b=\frac{\pi f}{Q \beta}
\end{aligned}
$$

where $x$ is distance from the source and $a$ is the intercept term that is regarded as the source intensity. The term $1 / x$ indicates the amplitude decay by geometrical spreading for the body wave, and exp $(-b x)$ indicates attenuation within the medium. This equation is the same as that used in the location of hypocenters of volcanic earthquakes by Battaglia and Aki (2003). As there are no marked later phases that correspond to surface waves (Figure 7), we used the geometrical spreading factor for body waves. The $b$ is connected with quality factor $Q$ with Equation 2, where $\beta$ denotes wave velocity.

Figure 8 shows the mean amplitudes at the seismic stations in each frequency band for shot 2. The amplitude 


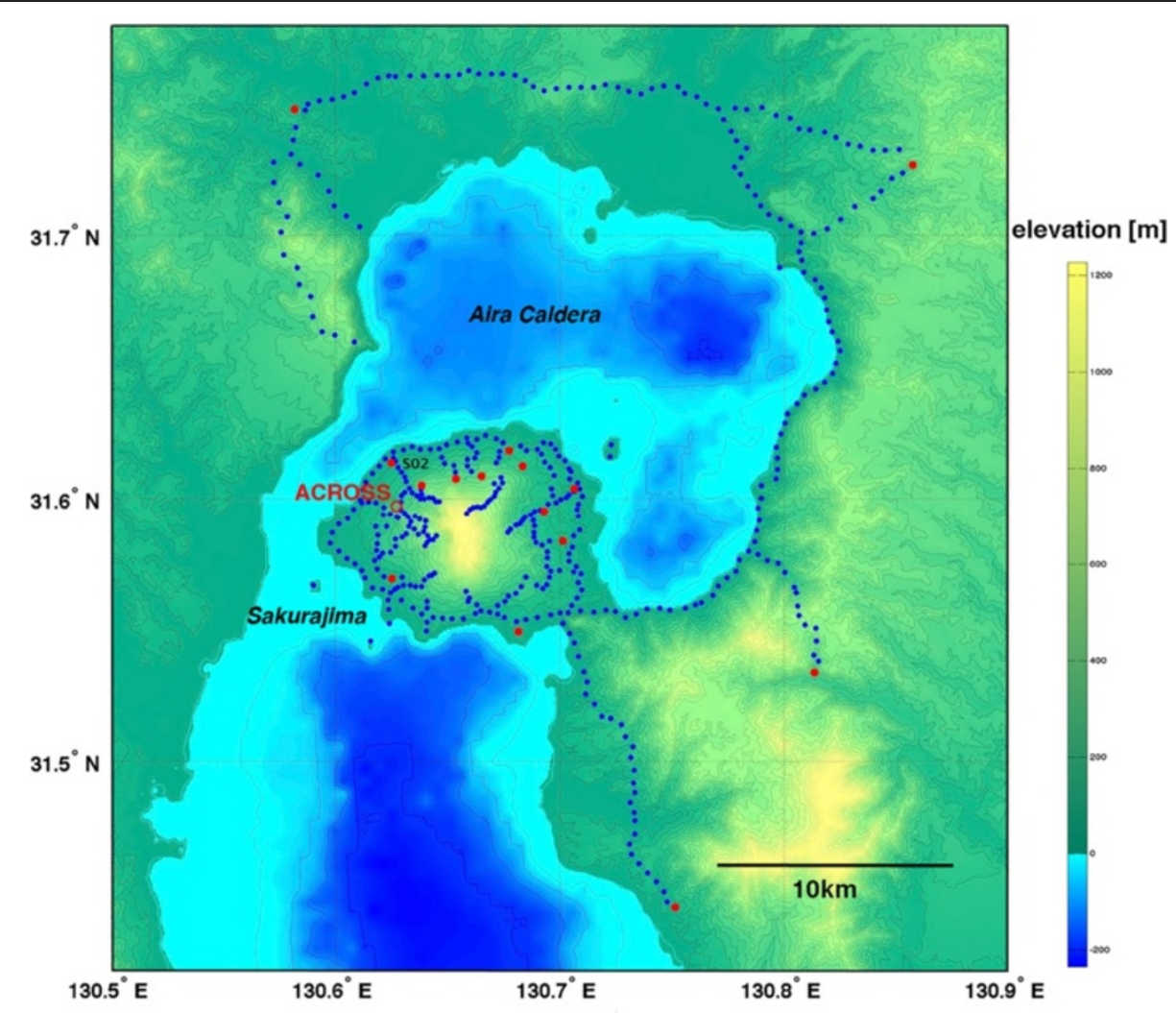

Figure 6 Location of seismometers and shots of explosion experiment (Iguchi et al. 2009) used in this study. Blue dots show the location of seismometers, and red dots show shot locations. The shot labeled S02 is used for the estimation of the amplitude decay as a function of distance in and around Sakurajima Volcano. Red open circle denotes the location of ACROSS source. The elevation is shown by color scale, where land area is colored in green to yellow and sea area is colored in cyan to blue.

values cover the distance range of 1 to $20 \mathrm{~km}$, which show the systematic decay of amplitude with distance. The blue dots show the mean amplitudes for the stations on Sakurajima Island, whereas black dots show those of the stations off it. We try two curve fits for each frequency band. We fit the data to minimize the sum of the fitting error in logarithmic amplitudes. The blue lines show the curve fits for the stations only on Sakurajima Island. The black lines show the curve fits for all the stations. The decay for the stations on Sakurajima Island is larger than that for all the stations. The former yields a $b$ value of about 0.25 for 5 to $15 \mathrm{~Hz}$ and 0.30 for 10 to $20 \mathrm{~Hz}$; the latter yields a $b$ value of about 0.17 for 5 to $15 \mathrm{~Hz}$ and 0.20 for 10 to $20 \mathrm{~Hz}$. Each value corresponds to $Q$ values of about $50,65,80$, and 100 , respectively, assuming that the $P$ wave velocity is $2.4 \mathrm{~km} \mathrm{~s}^{-1}$ based on the structure analysis of Sakurajima Island by Miyamachi et al. (2013). There are at least two reasons why the decay rates are different between the stations on and off Sakurajima Island. One is the difference in $Q$. Sakurajima Island is more attenuating than the surrounding region. The other is the difference in the nature of geometrical spreading. As seen in Figure 7, some of the traces off Sakurajima Island have marked later phases, which can be interpreted as a trapped wave in the soft sediments. Moreover, part of the seismic wave may propagate in the water surrounding the bay to transmit energy more effectively.

In this calculation, we used the horizontal distances between the source and the receivers. Let us examine the decay change when the distance along the ray for more realistic velocity structure is used. To examine the difference, we try to use the one-dimensional velocity structure that follows a simple linear function. We assume a velocity gradient of $0.5 \mathrm{~km} \mathrm{~s}^{-1} \mathrm{~m}^{-1}$ and surface velocity of $3.5 \mathrm{~km} \mathrm{~s}^{-1}$, which provides a maximum depth of $5.2 \mathrm{~km}$ for the ray traveling $25 \mathrm{~km}$ from the source. The corresponding $b$ values for the ray-based distance are $0.16,0.19,0.11$, and 0.13 , respectively. These values provide $Q_{p}$ of $80,100,120$, and 150 , respectively. The differences between the two estimations of $Q$ are about $50 \%$, which is the uncertainty owing to the model difference of the velocity structure.

It is interesting to compare these $Q_{p}$ values with those obtained in other methods or other volcanoes. Iguchi (1994) estimated the $Q_{p}$ value of Sakurajima Volcano using the spatial decay of amplitude of volcanic earthquakes and 


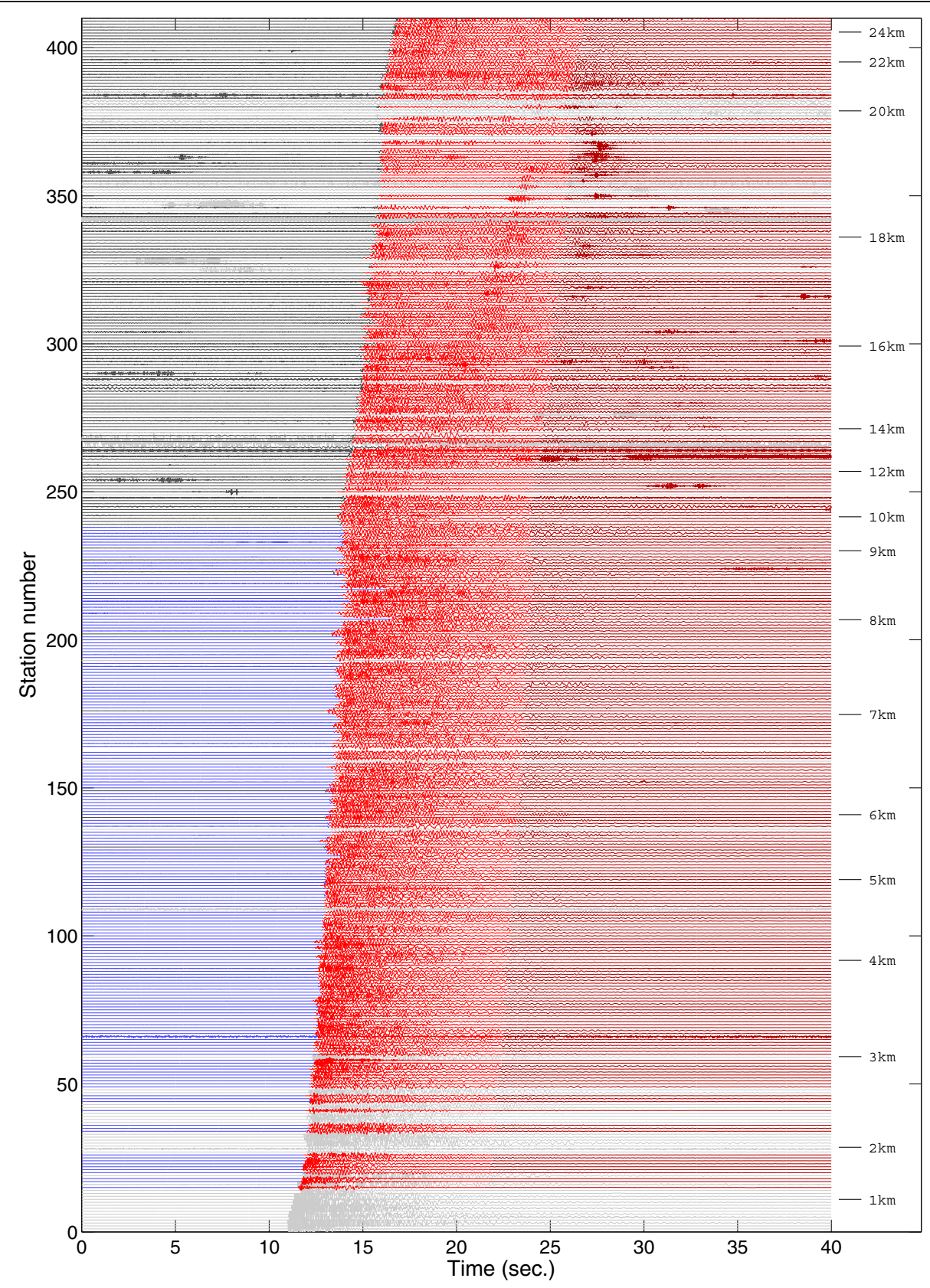

Figure 7 Seismograms that are aligned according to the distance for the explosion shot 2. The epicenter distance from the shot point is labeled on the right. Traces on Sakurajima Island are shown by blue lines before the first arrivals; those off it are shown by black lines. The traces drawn in gray color are not used in the analysis because of data clipping, noisy records, or failures. The first $10 \mathrm{~s}$ from the first arrivals is used for the analysis, which is shown in bright red.

obtained the $Q_{p}$ value of about 20. He used A-type earthquakes, in which short-period component of around $10 \mathrm{~Hz}$ predominates, with straight-line approximation of ray path between the epicenters and seismic stations in the island. As he assumed body wave for geometrical spreading factor, his $Q_{p}$ value can be directly compared with our result, which is about 50 . His result is smaller than ours, which may result from the hypocenter locations of A-type earthquakes, being just beneath the summit crater with depths of 1 to $4 \mathrm{~km}$. Low $Q_{p}$ value may indicate the high attenuation nature in the region beneath the summit crater. Hirata and Uchiyama (1981) estimated the attenuation in the Aira Caldera region, which neighbors Sakurajima Volcano, with spatial amplitude decay ratio, 

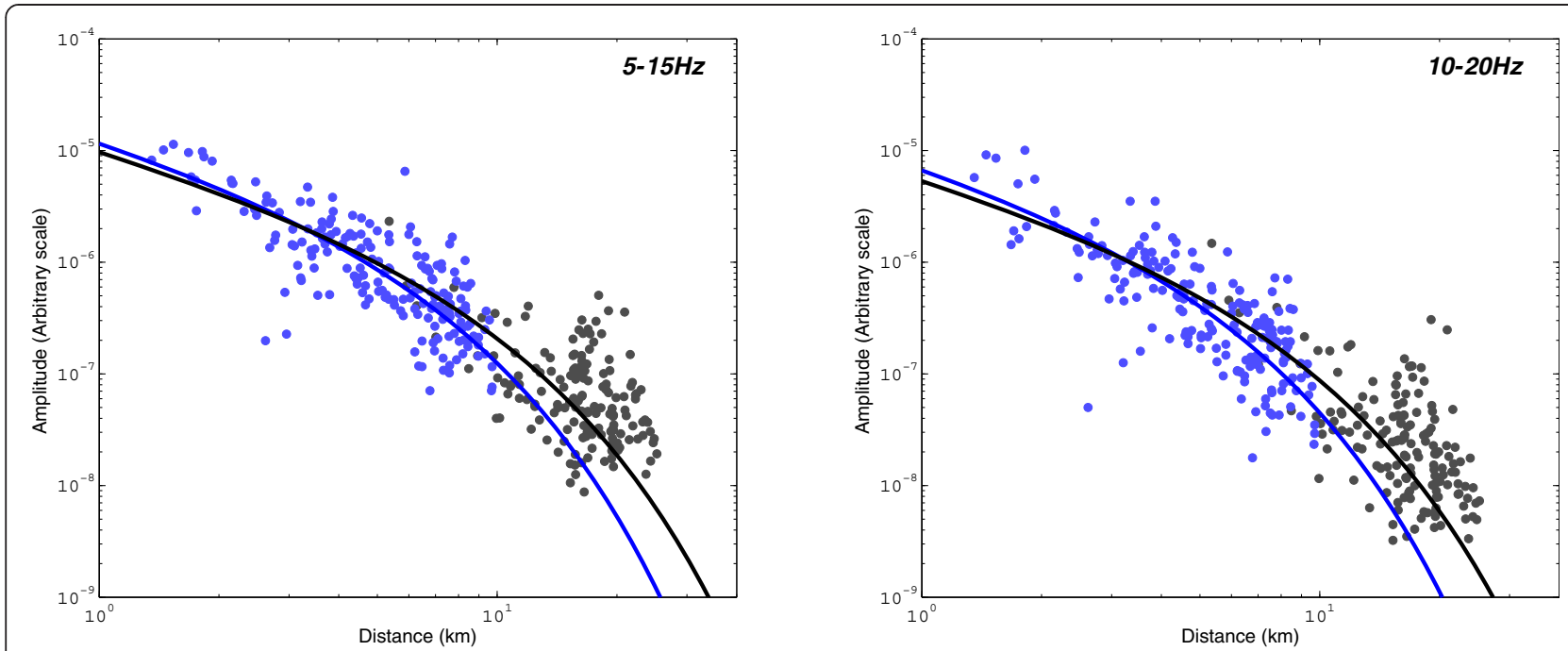

Figure 8 Mean spectral amplitudes of the signal from shot $\mathbf{2}$ for two frequency bands at seismic stations. The amplitudes are calculated using the first $10 \mathrm{~s}$ after the onset of the initial arrival of the shot signal (see Figure 7). Blue and black dots indicate the mean spectral amplitudes on and off Sakurajima Island, respectively. Blue and black solid lines show the approximation curve from Equation 1 for the stations on Sakurajima Island and all the stations, respectively.

showing a $Q_{p}$ of about 80. This supports our inference that the region of low $Q$ value estimated by Iguchi (1994) is localized near the vent.

$Q$ values are estimated for other volcanoes. Sudo (1991) estimated the attenuation beneath Aso Volcano, Japan, concluding that the $Q_{p}$ is about 100 . Bianco et al. (1999) estimated the $Q_{p}$ at Mt. Vesuvius, Italy, to be about 35 with the frequency decay method. Patane et al. (1994) estimated the attenuation using the records of seismic stations around Mt. Etna, showing that the $Q_{p}$ varies between 50 and 110 among the stations in the frequency range of 2 to $15 \mathrm{~Hz}$. Giampiccolo et al. (2007) estimated the attenuation at Mt. Etna to fit the power law $Q=Q_{f} f^{n}$ with the spectral ratio method. They found that $Q_{p}$ for the upper $5 \mathrm{~km}$ of the crust was estimated to be $16 f^{0.8}$ with some ambiguity, that is about 100 at $10 \mathrm{~Hz}$. Martinez-Arevalo et al. (2005) built the 3-D attenuation tomography in the shallow part $(-2$ to $2 \mathrm{~km}$ depth) at Mt. Etna and showed the large heterogeneity in $Q_{p}$, ranging between 10 and 250 , in the frequency range of 2 to $30 \mathrm{~Hz}$. They also found a region of low $Q_{p}$ between 10 and 30 at the place of presumed dike intrusion in 2001. The $Q_{p}$ we obtained for Sakurajima Volcano is comparable to the $Q_{p}$ values in other volcanoes.

\section{Amplitude decay in Tokai}

We compare these results with the amplitude decay relation obtained for the ACROSS sources at the Toyohashi site in the Tokai region. The same model of vibrators as used in Sakurajima has been in operation at Toyohashi site since 2007. At this site, two vibrators are operated with frequency modulation of different frequency bands, from 5 to $15 \mathrm{~Hz}$ and 10 to $20 \mathrm{~Hz}$. We used 26 seismic stations in the Tokai region for the analysis (Figure 9). Out of 26 stations, 24 are Hi-net stations that belong to NIED, and the other two are operated by Nagoya University. The data are stacked for 24 months to calculate the mean value of the spectral amplitudes that correspond to the signal range of the ACROSS sources. The mean spectral amplitudes are calculated as for the source at Sakurajima, i.e., RMS amplitudes of the spectral peaks within the operation frequency band for two components of synthesized linear vibration are calculated for each station. The spectral amplitudes at the stations are fit to Equation 1 to obtain the amplitude decay with distance.

Figure 10 shows the mean amplitude of the spectral signal of the ACROSS source at the Toyohashi site. In this plot, we used the signal of the source that is in FM operation between 10 and $20 \mathrm{~Hz}$, which includes the operation range of the ACROSS at Sakurajima. The mean amplitudes for both transverse and radial vibrations are plotted, showing no systematic difference between the vibration directions at the source. The values cover the distance range of up to $50 \mathrm{~km}$, though few stations exist at less than $10 \mathrm{~km}$ distance. They show the systematic decay of amplitude with distance. We fit the plot with Equation 1 as we did for the explosion experiment data in Sakurajima. The best-fit curve, which is shown by the blue line, yields an $a$ value (source intensity) of about $2.2 \times 10^{-9} \mathrm{~m} / \mathrm{s}$ and the $b$ value of about 0.049 , showing that the Tokai region is less attenuating than Sakurajima.

We predict the amplitude decay relations as a function of distance for the ACROSS source at Sakurajima from that in Tokai. We assume that both relations for Sakurajima 


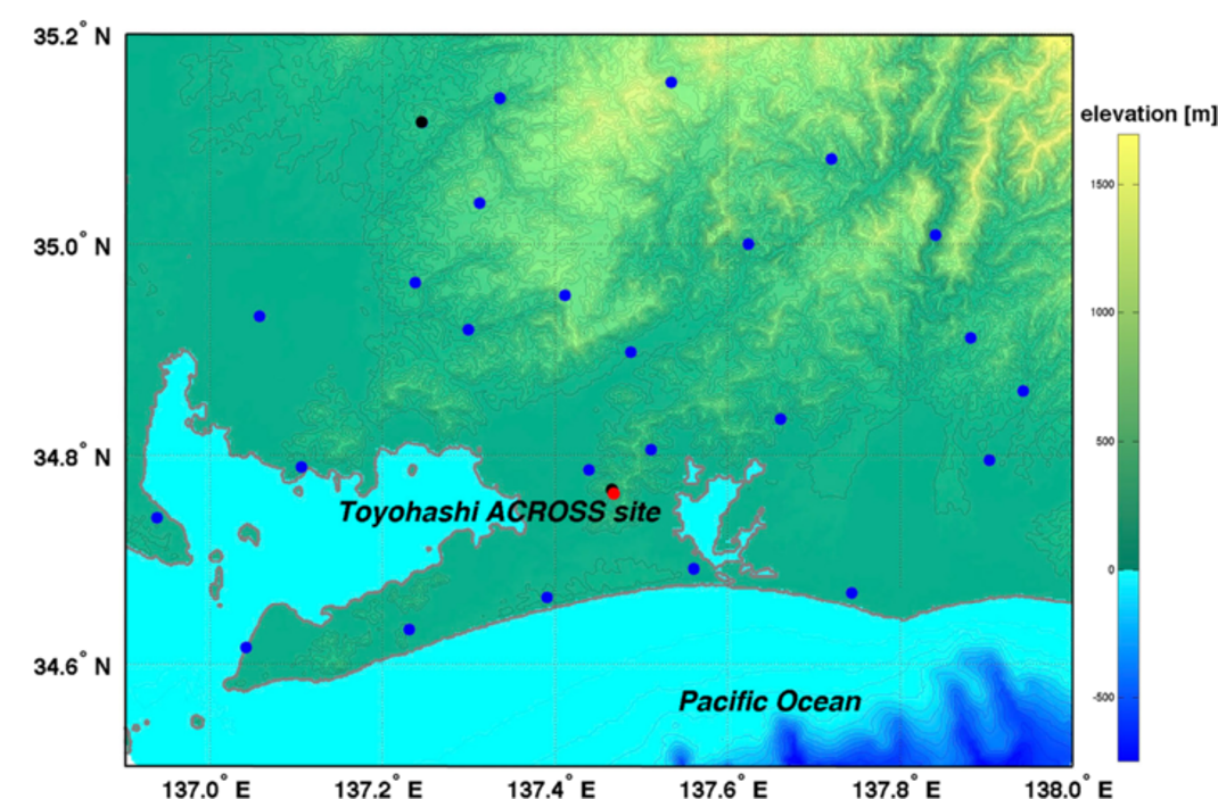

Figure 9 Location of seismic stations and ACROSS source used to estimate amplitude decay in Tokai region. Red dot indicates the ACROSS source site at Toyohashi. Blue dots indicate the seismic stations used in this study.

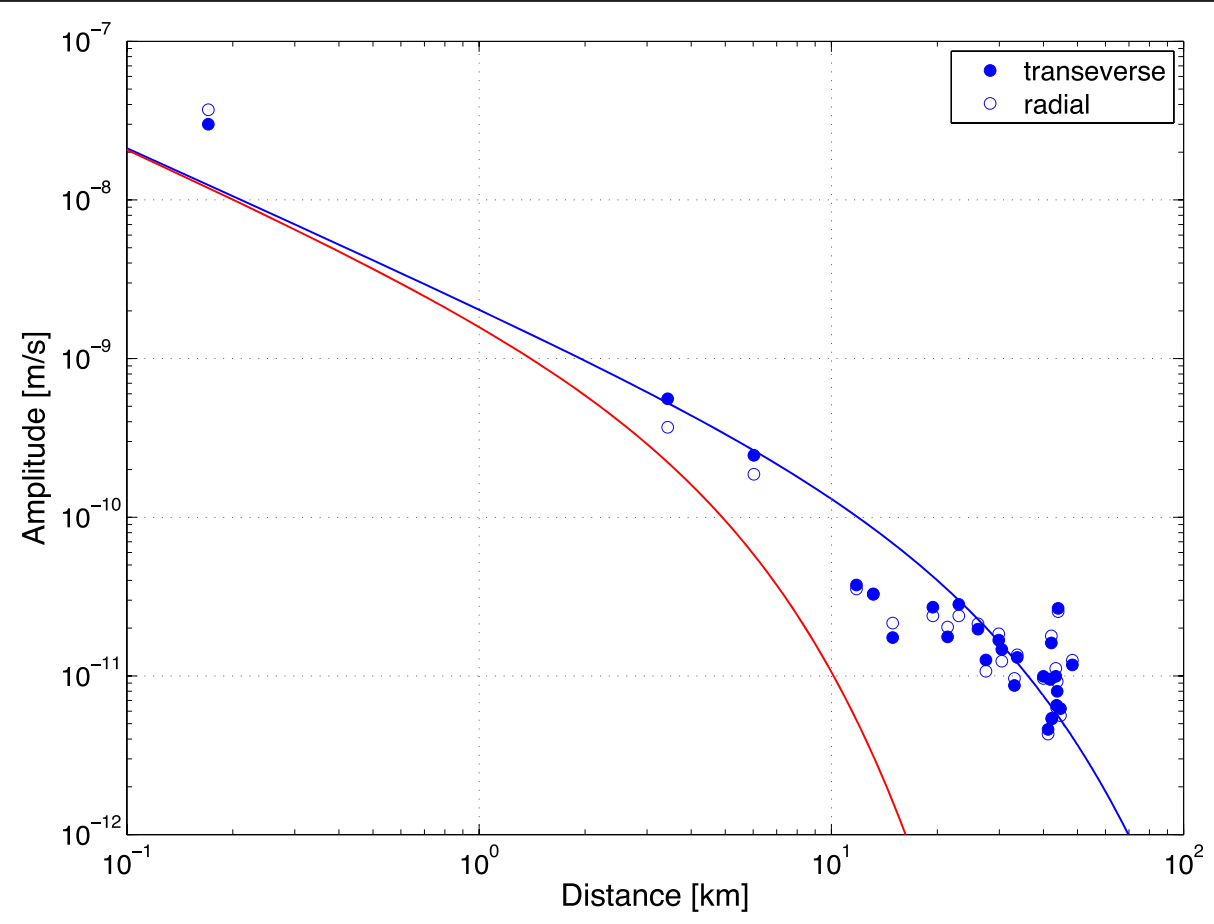

Figure 10 Signal amplitudes of ACROSS at Toyohashi site observed at regional seismic stations shown in Figure 9. Mean spectral amplitudes for both transverse (solid circle) and radial (open circle) components between 10 and $20 \mathrm{~Hz}$ are plotted. Blue line shows the approximation curve for the amplitude decay around the Toyohashi ACROSS site. Red line shows the decay model using the source intensity at Toyohashi and the attenuation in Sakurajima Island. 
and the Tokai region share the same source intensity $a$ in Equation 1, but that each has its own $b$ that is characteristic of each region. The red curve in Figure 10 indicates the predicted amplitude decay with distance for the ACROSS source in Sakurajima Volcano. In this curve, we use $b=$ 0.30 that is obtained for the stations on Sakurajima Island. Both lines run very close to each other below $1 \mathrm{~km}$, and the curve for Sakurajima decays more rapidly and becomes one tenth of the curve for Tokai region at $10 \mathrm{~km}$.

\section{Discussion}

\section{Comparison}

We compare the amplitude decay curve that is predicted for Sakurajima with the actual data we obtained in the first operation test. As the decay curve in Figure 10 is obtained from the FM operation from 10 to $20 \mathrm{~Hz}$ at the Toyohashi site, and the data in the first operation test in Sakurajima are obtained by the FM operation from 10 to $15 \mathrm{~Hz}$ and a single frequency of $10.01 \mathrm{~Hz}$, we need to convert their amplitudes to be able to compare them with each other. Therefore, we convert the amplitude decay curve that is predicted for FM operation of 10 to $20 \mathrm{~Hz}$ into the decay curve for FM operation of 10 to $15 \mathrm{~Hz}$. We also convert the amplitude of the single frequency of $10.01 \mathrm{~Hz}$ to the mean spectral amplitude of FM operation of 10 to $15 \mathrm{~Hz}$.

In the conversion, we make two assumptions. One is that the energy of the ACROSS signal is the sum of the square of the peaks in the amplitude spectrum. The other is that the attenuation is the same for the frequency range in this study. Based on these assumptions, we make the conversion as described below.

We first describe the conversion from the FM operation of 10 to $20 \mathrm{~Hz}$ into that of 10 to $15 \mathrm{~Hz}$. The frequency modulation of rotational velocity generates a force as

$$
F(t)=C f(t)^{2} \sin [2 \pi f(t) t]
$$

where $C$ is a constant that depends on the eccentricity of the rotor in the vibrator. Therefore, we may use the same $C$ for the vibrator using the same rotor. $f(t)$ is the rotational frequency as a function of time in the FM operation. As the source signal is generated by a centrifugal force of an eccentric mass, the signal amplitude is also modulated proportionally to $f(t)^{2}$. In our experiment, the rotational frequency linearly increases and decreases with time as

$$
\begin{array}{lrl}
f(t) & =f_{0}+\left(f_{1}-f_{0}\right) t / T & \left(0<t<T_{1}\right) \\
f(t)=f_{0}+\left(f_{1}-f_{0}\right)(t-T) /\left(T_{1}-T\right) & \left(T_{1}<t<T\right)
\end{array}
$$

where $T$ is the modulation length of rotational frequency, $f_{0}$ and $f_{1}$ represent the lower and upper bound of the modulation frequency, and $T_{1}$ is the time to switch the frequency from upsweep to downsweep. Using these equations, we calculate the energy ratio between the two FM operations by integrating the square of the force (Equation 3) over the modulation period $T$. The calculated energy ratio of the FM operation at 10 to $15 \mathrm{~Hz}$ to that at 10 to $20 \mathrm{~Hz}$ is 0.425 . As the number of spectral peaks for FM operation at 10 to $15 \mathrm{~Hz}$ is half of that at 10 to $20 \mathrm{~Hz}$, the mean energy ratio for one peak is $0.425 / 0.5=0.85$. The ratio in amplitude is the square root of energy ratio; the mean spectral amplitude for FM operation at 10 to $15 \mathrm{~Hz}$ is 0.92 times at 10 to $20 \mathrm{~Hz}$. The amplitude decay curve for Sakurajima in Figure 11 is drawn for the source intensity that is 0.92 times larger than that of Figure 10.

Next, we convert the amplitude of the spectral peak of single frequency operation at $10.01 \mathrm{~Hz}$ into the corresponding mean amplitude of FM operation of 10 to $15 \mathrm{~Hz}$. We calculate the energy ratio between single frequency operation at $10.01 \mathrm{~Hz}$ and FM operation of 10 to $15 \mathrm{~Hz}$. The energy ratio is calculated by integrating the square of the force by FM operation (Equation 3) and single frequency over the same period $T$. The calculated energy ratio of the FM operation over the single frequency is 2.627. Assuming the energy is equally distributed into 251 peaks between 10 and $15 \mathrm{~Hz}$, the calculated mean amplitude is 0.102 times that of the single frequency of $10.01 \mathrm{~Hz}$.

The converted amplitudes are plotted in Figure 11. In the figure, we plot the results of two types of amplitude averaging. One is the averaging over the receiver components (left panel), and the other is the averaging over the source excitations (right panel). As explained in the 'First signal test' section, the transfer function for each station has six components, which is the combination of two components for the source excitations and three components for the receiver. The panel on the left shows the mean amplitude of three components at receivers for transverse and radial excitations of the source. The mean amplitudes for the single sinusoid operation at $10.01 \mathrm{~Hz}$ are labeled $10.01 \mathrm{t}$ and $10.01 \mathrm{r}$ for transverse and radial excitations, respectively. Those of the FM operations are labeled FM $\mathrm{t}$ and FM r. There is no systematic difference in the mean amplitude between transverse and radial excitations. The panel on the right shows the amplitudes of transverse and radial components of the horizontal motions at receivers averaged over two excitation components of the source. There is no systematic difference in the receiver components.

In Figure 11, two decay curves are drawn. Red curves are the same as that in Figure 10, which use the $b$ value for the attenuation on Sakurajima Island. The black curves show the decay corresponding to the $b$ value for the attenuation on and around Sakurajima Island. The decay trend of observation amplitude is similar to what 

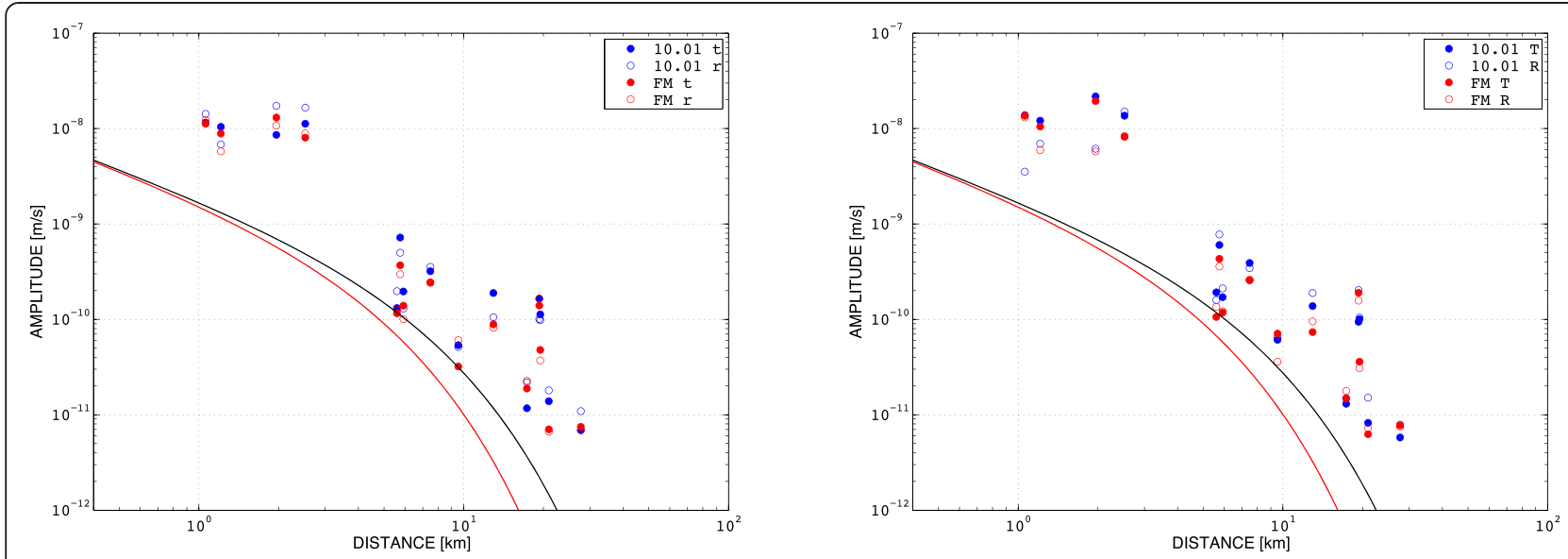

Figure 11 Comparison between predicted and observed amplitude decay of ACROSS signal in Sakurajima. Plots of amplitudes are the same as in Figure 4, except for the single sinusoid at $10.01 \mathrm{~Hz}$, which are converted to the equivalent value for the mean amplitude of FM operation between 10 and $15 \mathrm{~Hz}$. The left panel shows the amplitude at each seismic station averaged over the receiver components. The right panel shows the amplitude averaged over the source excitations. Red and black curves are the predicted amplitudes estimated in this study. The red curve is calculated using the amplitude data of the shot experiment on Sakurajima Island only, and the black curves use all the amplitude data on and off Sakurajima Island. The source intensity for the curves is equivalent to that of the FM operation at 10 to $15 \mathrm{~Hz}$, which is the operation frequency at Sakurajima. The source intensity is converted from that of ACROSS at Toyohasi, which is operated with frequency modulation at 10 to $20 \mathrm{~Hz}$, based on the force-frequency relationship of centrifugal force.

we have predicted in the above method, but most of the amplitudes are above the prediction curve.

Apparently, the reason for the discrepancy is the underestimation of the source intensity $a$. A possible reason for the underestimate is the difference in the deployment condition between Sakurajima and Toyohashi, i.e., stiffness of the ground to which the vibrator is fixed. The ACROSS vibrators at the Sakurajima site are deployed in a pyroclastic deposit, whereas those at the Toyohashi site are in a clay layer. The conversion efficiency from force to energy that is transmitted to the far field may depend on the stiffness of the ground where the vibrator is deployed. The simple analogy of strain energy in a compressed or stretched spring suggests that more strain energy is stored in a medium with less stiffness. Therefore, it is natural to infer that the vibrator transfers more far-field energy from the source that is deployed in the ground with less stiffness. In other words, the ground coupling is better at the Sakurajima site than at the Toyohashi site, which results in larger source intensity $a$ for Sakurajima even if the same vibrator is used. The ground coupling is the issue of dynamic interaction of vibrators and the surrounding ground, which is to be solved in future work. Mass of the vibrators and elastic nature of the ground may affect the coupling efficiency.

Another possible reason for the underestimate of source intensity $a$ could be the use of epicenter distances rather than the distances along ray paths. We try to evaluate the effect of the use of ray path-based distance on the source intensity with one-dimensional simple velocity structure model for Tokai area as in the section
'Explosion experiment at Sakurajima'. We assume a velocity gradient of $0.13 \mathrm{~km} \mathrm{~s}^{-1} \mathrm{~m}^{-1}$ and surface velocity of $4.5 \mathrm{~km} \mathrm{~s}^{-1}$, which gives a maximum depth of $7.4 \mathrm{~km}$ for the ray traveling $48 \mathrm{~km}$ of epicenter distance. The source intensity that is estimated by using the distance along ray paths is just $10 \%$ more than that by epicenter distances. Therefore, the use of epicenter distance is not the main cause of the underestimate.

Surface deployment of a seismometer may record a signal with large amplitude. The two stations between 2.0 and $3.0 \mathrm{~km}$ in Figure 11 are deployed on the surface (Tameguri et al. 2011), showing a larger amplitude compared with other stations, which are deployed in boreholes.

\section{Noise level}

Once the amplitude decay curve is obtained, the SNR is predicted using the level of ground noise at the seismic stations. Resolution of temporal variation of the ACROSS signal depends on the SNR after the data stacking (Ikuta et al. 2002). We have estimated the noise level in and around Sakurajima Volcano using the same seismic data of the explosion experiment as used in the previous section. We picked up 10-s-long records before the onset of the $P$ wave in the data at each station to estimate the noise level. We calculated the RMS of the amplitude spectrum of the noise in the frequency bands between 10 and $20 \mathrm{~Hz}$. This value is recognized as the noise level in the corresponding frequency range. We carried out this calculation on the data from each station for all the 15 shot sources. We adopted the third lowest value of 15 data as the representative noise level at each station. This 
operation avoids the traffic noise that occasionally disturbs the signal, as well as the artificially small noise level that might be due to the missed selection of amplitude gain.

Figure 12 shows the noise levels for all the stations both on and off Sakurajima Island. Gray markers show the noise level at all stations for all shots. Red markers show the representative noise level at the stations on Sakurajima Island, and blue markers show those off it. Generally, the noise level on Sakurajima Island is smaller than that off it, probably because Sakurajima Island is less populated than the surrounding area. The mean noise level inside Sakurajima is about $2.0 \times 10^{-9} \mathrm{~m} / \mathrm{s}$ for 10 -s stacking. Assuming random nature of the noise, the noise level is reduced proportionally to the square root of the stacking length of the data, and we can compare it with the spectral plot in Figure 3.

The spectral plot for station KURN, for example, is created with the stacked data of 71 days. The noise level for 71 days is reduced by 783 times smaller than that for 10-s data. Therefore, the mean noise on Sakurajima Island is reduced to $2.5 \times 10^{-12} \mathrm{~m} / \mathrm{s}$ after stacking, which is comparable to the noise level at KURN between 10 and $20 \mathrm{~Hz}$. The noise level at HAR, which is also on Sakurajima, is almost the same level. This means that the noise estimation in this study is valid.
We shall compare the noise level with the amplitude decay relation as shown in Figure 11. The noise level for the 10 -s data is $2.0 \times 10^{-9} \mathrm{~m} / \mathrm{s}$, which is comparable to the predicted amplitude decay curves at $1.0-\mathrm{km}$ distance. The noise level after stacking of 1 day is reduced to $2.1 \times 10^{-11} \mathrm{~m} / \mathrm{s}$, which is comparable to the level of predicted curves at $10 \mathrm{~km}$, and is several times smaller than the actual observation.

\section{Conclusion}

Seismic sources, named ACROSS, are deployed at Sakurajima Volcano for the first time in volcanic area in March of 2012. Two sources are deployed at the northwestern flank of Sakurajima Volcano with a distance of $3.6 \mathrm{~km}$ from the main crater. Signals received by the seismic stations are investigated for the test operation from 12 June to 18 September 2012, in which sources are operated with a single frequency at $10.01 \mathrm{~Hz}$ and with frequency modulation of 10 to $15 \mathrm{~Hz}$. The signal of the ACROSS source is detectable even at the station off Sakurajima Island. The amplitudes and the decay relation with source distance are compared with the amplitude decay model established in the Tokai region for the ACROSS source. The amplitude decay relation with distance in Sakurajima using the ACROSS sources is predicted from the

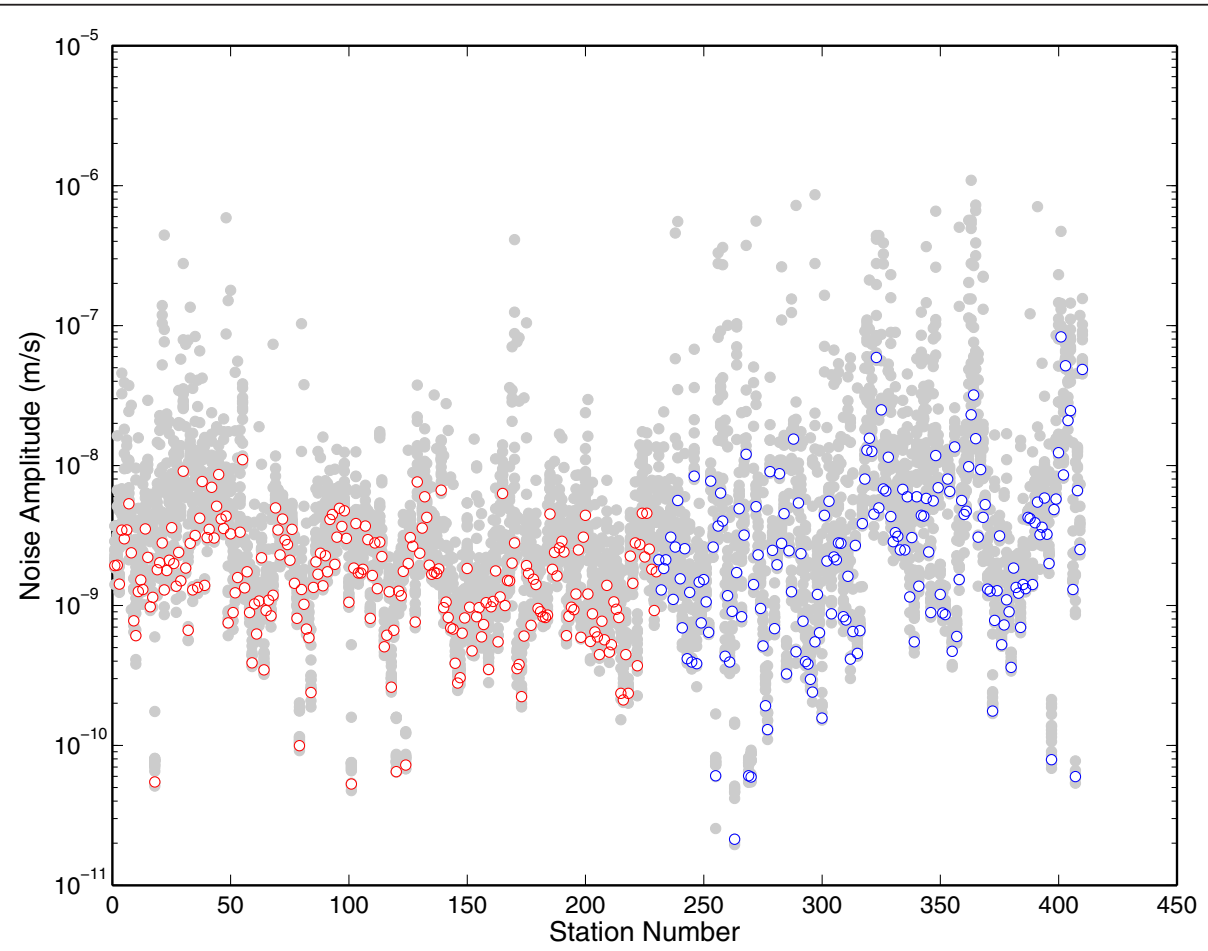

Figure 12 Levels of ground noise at temporary seismic stations used for the explosion experiment. Mean noise in the frequency domain between 10 and $20 \mathrm{~Hz}$ for 15 shots at all the stations is plotted with gray markers. The first $10 \mathrm{~s}$ of data before the first arrival of the shot signal is used for noise estimation (see Figure 7). Red and blue markers show the third smallest amplitudes among the 15 shot data for the stations on and off Sakurajima Island, respectively. 
amplitude data of an explosion experiment, assuming the same source intensity as that of the ACROSS source in the Tokai region. The predicted amplitude is systematically smaller than that actually observed, but the dependence with distance is consistent with the observation, probably because of the difference in the ground stiffness at the source site. The noise level in Sakurajima that is estimated using the data of explosion experiment is consistent with the noise in the stacking data of the ACROSS signal.

\section{Competing interests}

The authors declare that they have no competing interests.

\section{Authors' contributions}

KY made plans for instrument deployment, carried out the analyses, and drafted the manuscript. HM arranged the whole experiment at Sakurajima Volcano and maintained the long-term instrument operation. TW arranged the instrument deployment procedure. TK tuned up the instrument operation in detail. TM carried out the analyses in collaboration with KY. RI carried out the calculation to provide transfer functions. Ml provided the observation data and arranged the experiment at Sakurajima Volcano. All authors read and approved the final manuscript.

\section{Acknowledgements}

We are very grateful to the Sakurajima Volcano seismic exploration group for providing observation data for our analysis. We used the continuous data from seismic stations that are operated by National Research Institute for Earth Science and Disaster Prevention, Kyoto University, Kagoshima University, and Nagoya University. The study was supported by JSPS KAKENHI Grant-in-Aid for Scientific Research (B) 23340130.

\begin{abstract}
Author details
${ }^{1}$ Earthquake and Volcano Research Center, Graduate School of Environmental Studies, Nagoya University, Furo-cho, Chikusa-ku, Nagoya 464-8601, Japan. ${ }^{2}$ Graduate School of Science and Engineering, Kagoshima University, 1-21-35 Gunmoto, Kagoshima 890-0065, Japan. ${ }^{3}$ Faculty of Science, Shizuoka University, 836 Oya, Suruga-ku, Shizuoka 422-8529, Japan. ${ }^{4}$ Sakurajima Volcano Research Center, Disaster Prevention Research Institute, Kyoto University, 1722-19 Sakurajimayokoyama-cho, Kagoshima 891-1419, Japan. ${ }^{5}$ Current address: Earthquake Research Institute, the University of Tokyo, 1-1-1 Yayoi, Bunkyo-ku, Tokyo 113-0032, Japan. ${ }^{6}$ Current address: Sapporo Regional Headquarters, Japan Meteorological Agency, Chuo-ku, Sapporo 060-0002, Japan.
\end{abstract}

\section{Received: 3 October 2013 Accepted: 22 April 2014}

Published: 7 May 2014

\section{References}

Aramaki S (1969) Geology and pyroclastic flow deposits of the Kokubu area, Kagoshima prefecture. J Geolog Soc Japan 75:425-442

Battaglia J, Aki K (2003) Location of seismic events and eruptive fissures on the Piton de la Fournaise volcano using seismic amplitudes. J Geophys Res. doi:10.1029/2002JB002193

Bianco F, Castellano E, Del Pezzo E, Ibanez JM (1999) Attenuation of short-period seismic waves at Mt Vesuvius, Italy. Geophys J Int 138:67-76

Brenguier F, Sapiro NM, Campillo M, Ferrazzini V, Duputel Z, Coutant O, Nercessian A (2008) Towards forecasting volcanic eruptions using seismic noise. Nat Geosci 1:126-130

Crampin S (1994) The fracture criticality of crustal rocks. Geophys J Int 118:428-438

Gerst A, Savage MK (2004) Seismic anisotropy beneath Ruapehu volcano: a possible eruption forecasting tool. Science 306:1543-1547. doi:10.1126/science.113445

Giampiccolo E, D'Amico S, Patane D, Gresta S (2007) Attenuation and source parameters of shallow microearthquakes at Mt. Etna volcano, Italy. Bull Seismol Soc Am 97:184-197. doi:10.1785/0120050252

Grêt A, Roel S (2005) Monitoring rapid temporal change in a volcano with coda wave interferometry. Geophys Res Lett. doi:10.1029/2004GL021143
Hashimoto M, Tada T (1990) Crustal deformations associated with the 1986 fissure eruption of Izu-Oshima volcano, Japan, and their tectonic significance. Phys Earth Planet Int 60:324-338

Hidayati S, Ishihara K, Iguchi M (2007) Volcano-tectonic earthquakes during the stage of magma accumulation at the Aira caldera, southern Kyushu, Japan. Bull Volcanol Soc Japan 52:1289-1309

Hirata T, Uchiyama T (1981) Damping area in the Aira caldera of south Kyushu. Bull Seismol Soc Japan 34:435-437

Iguchi M (1994) A vertical expansion source model for the mechanisms of earthquakes originated in the magma conduit of an andesitic volcano: Sakurajima, Japan. Bull Volcanol Soc Japan 39:49-67

Iguchi M, Tameguri T, Yamamoto K, Osima H, Maekawa T, Mori H, Suzuki A, Tsutui T, Imai M, Tsushima K, Yagi N, Ueki S, Nakayama T, Yamamoto Y, Takagi R, li S, Koga S, Nishimura T, Anggono T, Yamamoto M, Oikawa J, Osada N, Ichihara M, Tsuji H, Aoki Y, Morita Y, Watanabe A, Nogami K, Yamawaki T, Watanabe T, et al. (2009) The 2008 project of artificial explosion experiment at Sakurajima volcano. Ann Disaster Prev Res Inst, Kyoto Univ 52:293-307

Ikuta R, Yamaoka K, Miyakawa K, Kunitomo T, Kumazawa M (2002) Continuous monitoring of propagation velocity of seismic wave using ACROSS. Geophys Res Lett. doi:10.1029/2001GL013974

Ikuta R, Yamaoka K (2004) Temporal variation in the shear wave anisotropy detected using the Accurately Controlled Routinely Operated Signal System (ACROSS). J Geophys Res. doi:10.1029/2003JB002901

Ishihara K, Takayama T, Tanaka Y, Hirabayashi J (1981) Lava flows at Sakurajima Volcano (I) - volume of the historical lava flows. Ann Disaster Prev Res Inst, Kyoto Univ 24:1-10

Ishihara K (1990) Pressure sources and induced ground deformation associated with explosive eruptions at an andesitic volcano: Sakurajima volcano, Japan. In: Ryan M (ed) Magma transport and storage. John Wiley and Sons, Chichester

Japan Meteorological Agency (2013) National catalogue of the active volcanoes in Japan, 4th edition. Japan Meteorological Agency, Tokyo

Kobayashi T, Tameike T (2002) History of eruptions and volcanic damage from Sakurajima volcano, southern Kyushu, Japan. Quaternary Res 41:269-278

Kumagai H (2006) Temporal evolution of a magmatic dike system inferred from the complex frequencies of very long period seismic signals. J Geophys Res. doi:10.1029/2005JB003881

Kumazawa M, Takei Y (1994) Active method of monitoring underground structures by means of accurately controlled rotary seismic source (ACROSS) 1. Purpose and principle. In: Abstracts of fall meeting of the Seismological Society of Japan, p 158

Kunitomo T, Kumazawa M (2004) Active monitoring of the Earth's structure by the seismic ACROSS - transmitting and receiving technologies of the seismic ACROSS. In: Proceedings of the 1st International Workshop on Active Monitoring in the Solid Earth Geophysics, Mizunami

Martinez-Arevalo C, Patane D, Rietbrock A, Ibanez JM (2005) The intrusive process leading to the Mt. Etna 2001 flank eruption: constraints from 3-D attenuation tomography. Geophys Res Lett 32:L21309

McNutt SR (1996) Seismic monitoring and eruption forecasting of volcanoes: a review of the state-of-the-art and case histories. In: Scarpa R, Tilling R (ed) Monitoring and mitigation of volcano hazards. Springer, New York, pp 99-146

Miyamachi H, Tomari C, Yakiwara H, Iguchi M, Tameguri T, Yamamoto K, Ohkura T, Ando T, Onishi K, Shimizu H, Yamashita Y, Nakamichi H, Yamawaki T, Oikawa J, Ueki S, Tsutsui T, Mori H, Nishida M, Hiramatsu H, Koeda T, Masuda Y, Katou K, Hatakeyama K, Kobayashi T (2013) Shallow velocity structure beneath the Aira caldera and Sakurajima volcano as inferred from refraction analysis of the seismic experiment in 2008. Bull Volcanol Soc Japan 58:227-237

Mogi K (1957) On the relation between the eruptions of Sakurajima Volcano and the crustal movements in its neighborhood. Bull Volcanol Soc Japan 1:9-18

Nishimura T, Tanaka S, Yamawaki T, Yamamoto H, Sano T, Sato M, Nakahara H, Uchida N, Hori S, Sato H (2005) Temporal changes in seismic velocity of the crust around Iwate volcano, Japan, as inferred from analyses of repeated active seismic experiment data from 1998 to 2003. Earth Planets Space 57:491-505

Okada Y (1985) Surface deformation due to shear and tensile faults in a half-space. Bull Seismol Soc Am 75:1135-1154

Omori F (1916) The Sakura-Jima eruptions and earthquakes II. Bull Imperial Earthquake Investigation Committee 8:35-179

Patane D, Ferrucci F, Cresta S (1994) Spectral features of microearthquakes in volcanic areas: attenuation in the crust and amplitude response of site at Mt. Etna, Italy. Bull Seismol Soc Am 84:1842-1860 
Sakai S, Yamada T, Ide S, Mochizuki M, Shiobara H, Urabe T, Hirata N, Shinohara M, Kanazawa T, Nishizawa A, Fujie G, Mikada H (2001) Magma migration from the point of view of seismic activity in the volcanism of Miyake-jima island in 2000. J Geography 110:145-155

Sasai Y, Uyeshima M, Zlotnicki J, Utada H, Kagiyama T, Hashimoto T, Takahashi Y (2002) Magnetic and electric field observation during the 2000 activity of Miyake-jima volcano, Central Japan. Earth Planet Sci Lett 203:769-777

Sens-Schoenfelder C, Wegler U (2006) Passive image interferometry and seasonal variations of seismic velocities at Merapi Volcano. Indonesia Geophys Res Lett. doi:10.1029/2006GL027797

Sudo Y (1991) An attenuating structure beneath the Aso Caldera determined from the propagation of seismic waves. Bull Volcanol 53:99-111

Tameguri T, Iguchi M, Sonoda T, Ichikawa N (2011) Hypocenter distributions of volcanic earthquakes at Sakurajima Volcano (2011-2012). In: Iguchi M (ed) Annual report of research on Sakurajima volcano with comprehensive observation. Disaster Prevention Research Institute of Kyoto University, Uji, Japan, pp 2-6

Tsutsui T, Tameguri T, Iguchi M, Oikawa J, Oshima H, Maekawa T, Aoyama H, Ueki S, Hirahara S, Nogami K, Ohminato T, Ichihara M, Tsuji H, Horikawa S, Okuda T, Shimizu H, Matsushima T, Ohkura T, Yoshikawa S, Sonoda T, Miyamachi H, Yakiwara H, Hirano S, Saito K, Suemine K, Goto S, Ikegami T, Kato K, Matsusue S, Kohno T, et al. (2011) The repeated seismic survey 2010 in Sakurajima Volcano, south Kyushu, Japan, the second round. Ann Disaster Prev Res Inst, Kyoto Univ 54:195-208

Yamaoka K, Kunitomo T, Miyakawa K, Kobayashi K, Kumazawa M (2001) A trial for monitoring temporal variation of seismic velocity using an ACROSS system. Island Arc 10:336-347

doi:10.1186/1880-5981-66-32

Cite this article as: Yamaoka et al: Active monitoring at an active volcano: amplitude-distance dependence of ACROSS at Sakurajima Volcano, Japan. Earth, Planets and Space 2014 66:32.

\section{Submit your manuscript to a SpringerOpen ${ }^{\circ}$ journal and benefit from:}

- Convenient online submission

- Rigorous peer review

- Immediate publication on acceptance

- Open access: articles freely available online

- High visibility within the field

- Retaining the copyright to your article

Submit your next manuscript at $\gg$ springeropen.com 